\title{
Designing Molecular Electrides from \\ Defective Unit Cells of Cubic Alkaline Earth Oxides.
}

\section{Supporting Information}

Maksim Kulichenko, ${ }^{a}$ Andrey N. Utenyshev, ${ }^{b}$ Konstantin V. Bozhenko ${ }^{b, c, *}$

a Department of Chemistry and Biochemistry, Utah State University, Logan 84322, Utah, USA.

b Institute of Problems of Chemical Physics, Russian Academy of Sciences, Chernogolovka 142432, Moscow Region, Russia.

c Lomonosov Moscow State University, Moscow 119991, Russia.

* e-mail: bogenko@icp.ac.ru
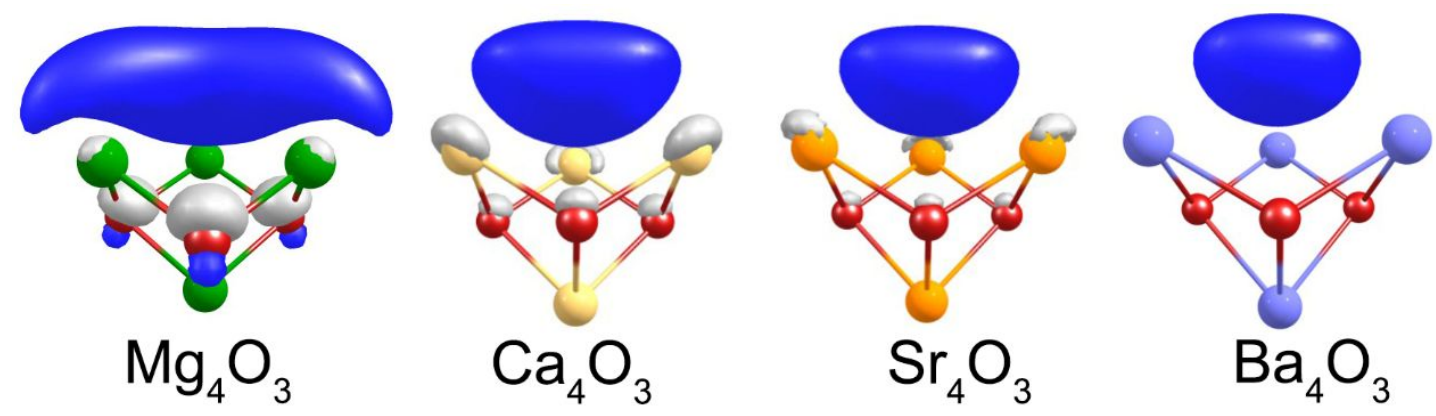

Figure S1. HOMOs of studied structures. Contour value is 0.043 .
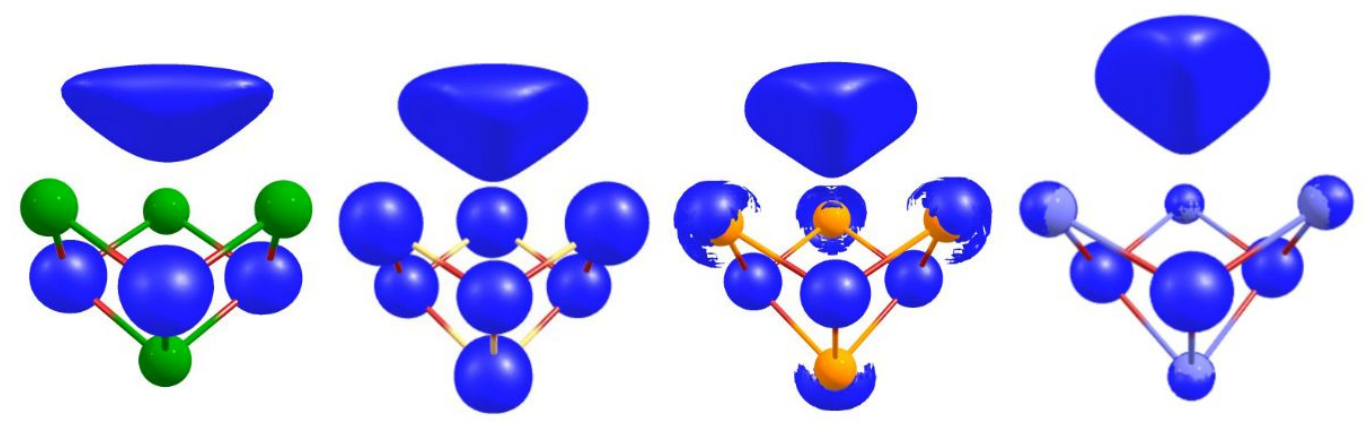

Figure S2. LOL isosurfaces of studied structures. Isovalue = 0.5. (PBE0-DKH/aug-cc-pVTZ-DK).

Table S1. GM of $\mathrm{Be}_{4} \mathrm{O}_{3}$

$\begin{array}{llll}4 & 2.141356000 & 0.844043000 & 0.979691000\end{array}$ 


\begin{tabular}{|c|c|c|c|}
\hline 4 & -0.496011000 & 2.611644000 & 0.860034000 \\
\hline 4 & 1.700912000 & 3.102590000 & 0.459846000 \\
\hline 4 & -0.110812000 & 0.636626000 & 1.314900000 \\
\hline 8 & 1.105869000 & -0.099888000 & 1.350026000 \\
\hline 3 & 0.369641000 & 3.675017000 & 0.480716000 \\
\hline 8 & 2.726936000 & 2.099801000 & 0.586576000 \\
\hline \multicolumn{4}{|c|}{ Table S2. GM Mg $\mathrm{O}_{3}$} \\
\hline 12 & -1.450362000 & 0.837367000 & -0.660272000 \\
\hline 12 & 1.450362000 & 0.837367000 & -0.660272000 \\
\hline 12 & 0.000000000 & -1.674734000 & -0.660272000 \\
\hline 12 & 0.000000000 & 0.000000000 & 1.372196000 \\
\hline 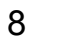 & 0.000000000 & 1.642065000 & 10000 \\
\hline 8 & 1.422070000 & -0.821032000 & 0.304310000 \\
\hline & -1.422070000 & 032000 & 0.304310000 \\
\hline \multicolumn{4}{|c|}{ Table S3. GM Ca ${ }_{4} \mathrm{O}_{3}$} \\
\hline 20 & 1.390745000 & -1.389034000 & -0.713268000 \\
\hline 20 & 0.5 & 000 & -0.7 \\
\hline 20 & -1.85 & 797000 & -0.713090000 \\
\hline 20 & 0.000012000 & -0.000111000 & 1.711767000 \\
\hline 8 & -1.198773000 & 1.197235000 & 0.356601000 \\
\hline 8 & -0.437175000 & 871000 & 0.356290000 \\
\hline & 1.636370000 & 0.439851000 & 0.356695000 \\
\hline \multicolumn{4}{|c|}{ Table S4. GM Sr${ }_{4} \mathrm{O}_{3}$} \\
\hline 38 & -1.842197000 & 1.063593000 & -0.72 \\
\hline 38 & $1.8421 \mathrm{c}$ & 93000 & -0.721511000 \\
\hline 38 & 0.000000000 & -2.127186000 & -0.721511000 \\
\hline 38 & 0.000000000 & 0.000000000 & 1.908382000 \\
\hline 8 & 0.000000000 & 1.747558000 & 0.405573000 \\
\hline 8 & 1.513430000 & -0.873779000 & 0.405573000 \\
\hline 8 & -1.513430000 & -0.873779000 & 0.405573000 \\
\hline \multicolumn{4}{|c|}{ Table S5. GM Ba $\mathrm{O}_{3}$} \\
\hline 56 & -0.000973000 & -0.002222000 & 2.081775000 \\
\hline 56 & -2.280799000 & -0.294909000 & -0.753247000 \\
\hline 56 & 0.884701000 & 2.123714000 & -0.750538000 \\
\hline 56 & 1.397057000 & -1.826465000 & -0.753246000 \\
\hline 8 & 1.757443000 & 0.227964000 & 0.410061000 \\
\hline 8 & -1.075896000 & 1.407499000 & 0.409809000 \\
\hline 8 & -0.681448000 & -1.636288000 & 0.406917000 \\
\hline
\end{tabular}

Table S6. At PBE0-DKH/aug-cc-pVTZ-DK level of theory.

\begin{tabular}{|l|l|l|l|}
\hline System & $\langle\alpha>$, a.u. & $\beta_{\text {tot }}$, a.u. & Excitation energy, eV \\
\hline $\mathrm{Be}_{4} \mathrm{O}_{3}$ & 66.79 & 524.61 & 5.25 \\
\hline $\mathrm{Mg}_{4} \mathrm{O}_{3}$ & 243.86 & 5689.96 & 2.06 \\
\hline $\mathrm{Ca} 4 \mathrm{O} 3$ & 508.11 & 37703.84 & 1.42 \\
\hline $\mathrm{Sr} 4 \mathrm{O} 3$ & 634.175 & 46218.29 & 1.31 \\
\hline $\mathrm{Ba} 4 \mathrm{O} 3$ & 837.99 & 65747.73 & 1.18 \\
\hline
\end{tabular}

Table S7. Dissociation energy of $\mathrm{Ca}_{4} \mathrm{O}_{3}$. (PBE0/def2-TZVP + ZPE).

\begin{tabular}{|l|l|}
\hline Fragments & Energy, $\mathrm{kcal} / \mathrm{mol}$ \\
\hline $\mathrm{Ca}_{2} \mathrm{O}_{2}+\mathrm{Ca}_{2} \mathrm{O}$ & 378088.9 \\
\hline
\end{tabular}




\begin{tabular}{|l|l|}
\hline $3 \times \mathrm{CaO}+\mathrm{Ca}$ & 298.5 \\
\hline $\mathrm{Ca}_{3} \mathrm{O}_{3}+\mathrm{Ca}$ & 81.9 \\
\hline $\mathrm{Ca}_{2} \mathrm{O}+2 \times \mathrm{CaO}$ & 378206.7 \\
\hline $\mathrm{Ca}_{3} \mathrm{O}_{2}+\mathrm{CaO}$ & 123.8 \\
\hline $4 \mathrm{Ca}+3 \mathrm{O}$ & 789.3 \\
\hline
\end{tabular}

